OAK RIDGE

NATIONAL

LABORATORY

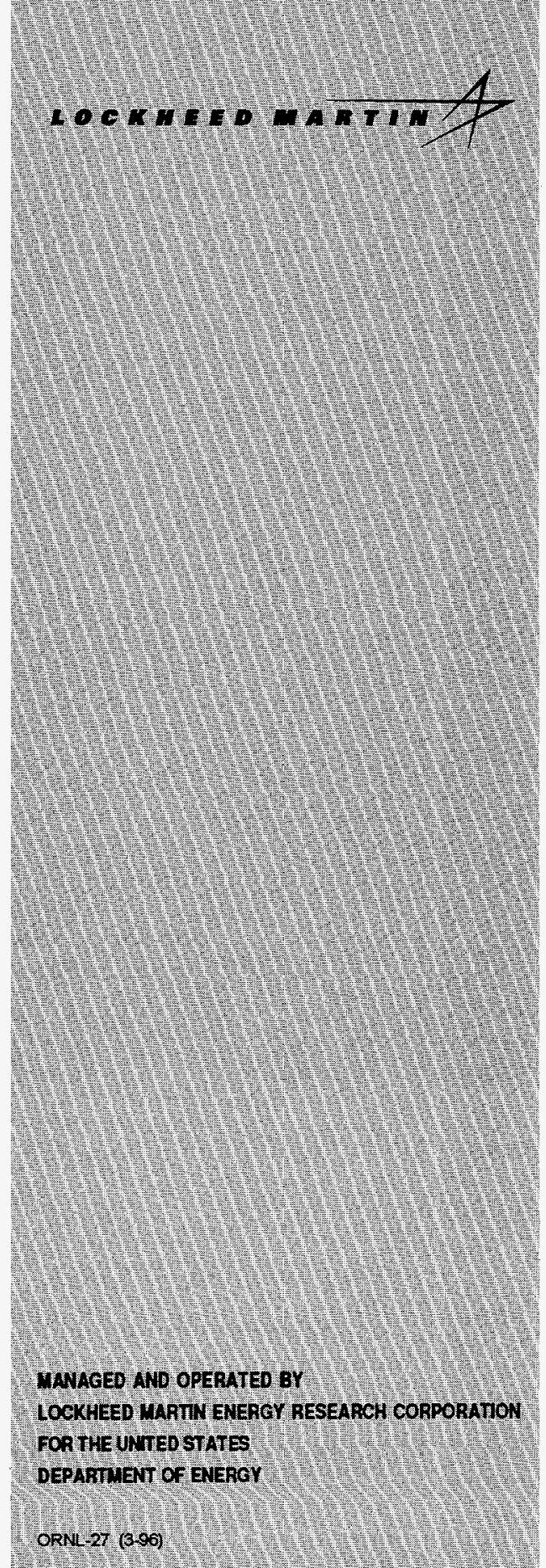

Test Plan for the Parallex CANDU-MOX Irradiation

G. L. Copeland
MASTER

$$
\begin{aligned}
& \text { RECEIVED } \\
& \text { JUL } 3 \text { I } 1997 \\
& \text { OSTI }
\end{aligned}
$$

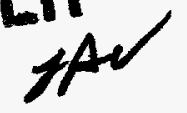


This report has been reproduced directly from the best available copy.

Available to DOE and DOE contractors from the Office of Scientific and Technical Information, P.O. Box 62, Oak Ridge, TN 37831; prices available from (423) 576-8401.

Available to the public from the National Technical Information Service, U.S. Department of Commerce, 5285 Port Royal Rd., Springfield, VA 22161.

This report was prepared as an account of work sponsored by an agency of the United States Government. Neither the United States Government nor any agency thereof, nor any of their employees, makes any warranty, express or implied, or assumes any legal liability or responsibility for the accuracy, completeness, or usefulness of any information, apparatus, product, or process disclosed, or represents that its use would not infringe privately owned rights. Reference herein to any specific commercial product, process, or service by trade name, trademark, manufacturer, or otherwise, does not necessarily constitute or imply its endorsement, recommendation, or favoring by the United States Government or any agency thereof. The views and opinions of authors expressed herein do not necessarily state or reflect those of the United States Government or any agency thereof. 


\section{DISCLAIMER}

Portions of this document may be illegible electronic image products. Images are produced from the best available original document. 
ORNL/TM-13302

Dist. Category UC-523

\title{
TEST PLAN FOR THE PARALLEX CANDU-MOX IRRADIATION
}
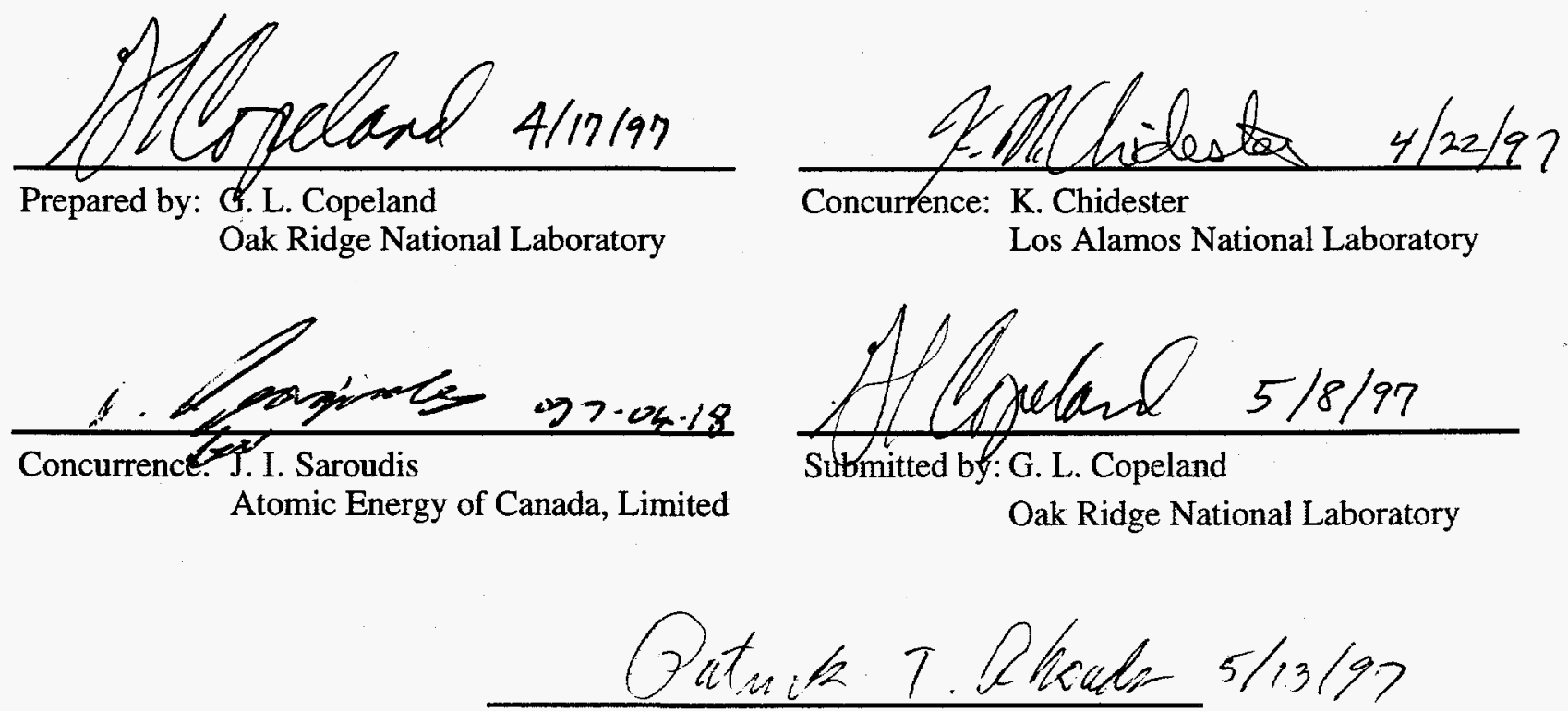

Approval: P. T. Rhoads

U.S. Department of Energy

Office of Fissile Materials Disposition

Published: June 1997

\author{
Prepared by the \\ OAK RIDGE NATIONAL LABORATORY \\ Oak Ridge, Tennessee 37831-6144 \\ managed by \\ LOCKHEED MARTIN ENERGY RESEARCH CORPORATION \\ for the \\ U. S. DEPARTMENT OF ENERGY \\ under contract DE-AC05-96OR22464
}




\section{Revision History}

\begin{tabular}{|c|c|c|}
\hline Revision number & Date issued & Reason for revision \\
\hline 0 & June 1997 & \\
\hline
\end{tabular}




\section{CONTENTS}

Page

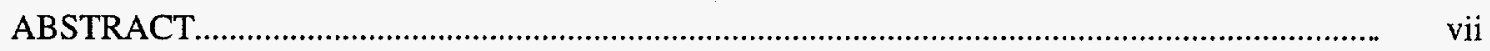

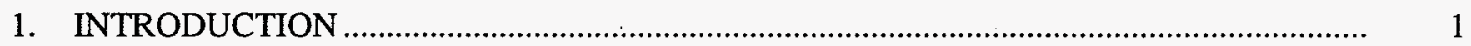

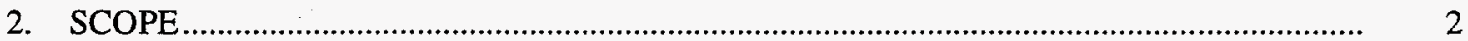

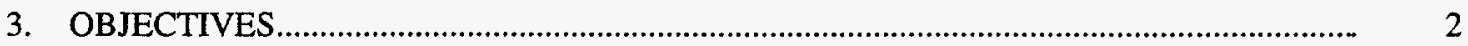

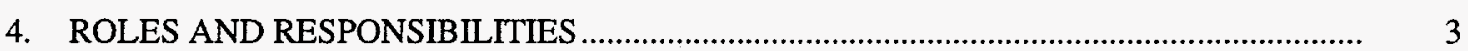

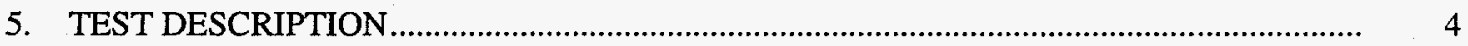

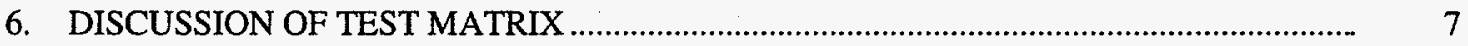

7. POSTIRRADIATION EXAMINATION ............................................................................. 9

8. QUALITY ASSURANCE REQUIREMENTS ........................................................................ 10

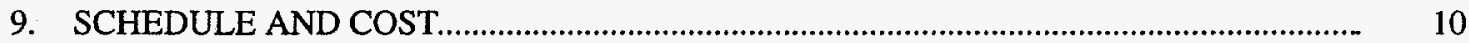

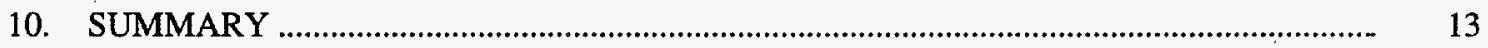

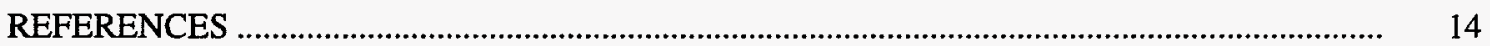





\begin{abstract}
One of several options being considered by the United States and the Russian Federation for the disposition of excess plutonium from dismantled weapons is to convert it to mixed-oxide (MOX) fuel for use in Canadian uranium-deuterium (CANDU) reactors. This report describes an irradiation test demonstrating the feasibility of this concept with laboratory quantities of MOX fuel placed in the pressurized loops of the National Research Universal test reactor at the Atomic Energy of Canada, Ltd., Chalk River Laboratories. The objective of the Parallex (for parallel experiment) test is to simultaneously test laboratory-produced quantities of U.S. and R.F. MOX fuel in a test reactor under heat generation rates representing those expected in the CANDU reactors. The MOX fuel will be produced with plutonium from disassembled weapons at the Los Alamos National Laboratory in the United States and at the Bochvar Institute in the Russian Federation. Thus, the test will serve to demonstrate the accomplishment of many parts of the disposition mission: disassembly of weapons, conversion of the plutonium to oxide, fabrication of MOX fuel, assembly of fuel elements and bundles, shipment to a reactor, irradiation, and finally, storage of the spent fuel elements awaiting eventual disposition in a geologic repository in Canada.
\end{abstract}




\section{INTRODUCTION}

One of the options being considered by the United States and the Russian Federation (R.F.) for the disposition of excess plutonium from dismantled weapons is to convert it to mixed-oxide (MOX) fuel for utilization in Canadian deuterium-uranium (CANDU) reactors. The Canadian government with Atomic Energy of Canada, Limited, (AECL) and Ontario Hydro have agreed to consider using the four Bruce A reactors for this mission. In advance of the selection of final options, the Fissile Materials Disposition Program (FMDP) of the U.S. Department of Energy Office of Materials Disposition (USDOE-MD) initiated this test to demonstrate the feasibility of this concept with laboratory quantities of MOX fuel placed in the pressurized loops of the National Research Universal (NRU) test reactor at the AECL Chalk River Laboratories (CRL). Demonstration tests are also under way for the light-water reactor (LWR) options in both the United States and the Russian Federation. The objective of the Parallex (for parallel experiment) test is to simultaneously test laboratory-produced quantities of U.S. and R.F. MOX fuel in a test reactor under conditions similar to those expected in the Bruce reactors. The MOX fuel will be produced with plutonium from disassembled weapons at the Los Alamos National Laboratory (LANL) in the United States and at the Bochvar Institute in the Russian Federation. Thus, the test will serve to demonstrate the accomplishment of many parts of the disposition mission: disassembly of weapons, conversion of the plutonium to oxide, fabrication of MOX fuel, assembly of fuel elements and bundles, shipment to a reactor, irradiation, and finally storage of the spent fuel elements awaiting eventual disposition in a geologic repository in Canada.

Since the initiation of Parallex test activities in May 1996, several events have influenced the schedule and scope of the test. First, negotiation with the Russian Federation failed to advance quickly enough for them to fabricate fuel for the desired December 1996 insertion of the first test bundle. These negotiations are advancing now, and a contract is expected to be finalized in June 1997. If this occurs, the first bundle could be inserted in early 1998. Second, fuel fabrication at LANL during the period May-December 1996 resulted in completion of only one type of fuel rather than the four types planned. Third, the Record of Decision $^{1}$ (ROD) was issued on January 14, 1997, and retained the option to disposition plutonium in CANDU reactors in the event that a multilateral agreement is reached among the United States, the Russian Federation, and Canada for joint disposition of some portion of the U.S./R.F. plutonium. That is, the CANDU option is not to be considered solely for the U.S. plutonium. These events have combined to place contingencies on the scope of the test. The original scope was for four bundles of joint U.S./R.F. fuel to be tested. The current plan is to insert one joint U.S.R.F. bundle into NRU in early 1998. The other three bundles are contingent on the outlook for U.S./R.F./Canada negotiations on the CANDU option, funding availability for additional fuel fabrication at LANL, and the availability of LANL facilities for the fabrication. Thus, throughout this plan, the first bundle refers to the currently planned one-bundle test (fixed bundle BD-1), the full test refers to the original four-bundle test matrix, and the contingency bundles refer to the three bundles other than the first. 


\section{SCOPE}

The current scope of the Parallex test is limited to those actions required to fabricate, irradiate, and examine one experimental bundle of CANDU MOX fuel containing plutonium from disassembled weapons in the United States and the Russian Federation. The conversion of the plutonium from weapons components (pits) to $\mathrm{PuO}_{2}$ is not a part of the test, but is a prerequisite. The fabrication of fuel pellets meeting the AECL specifications will be accomplished through blending the $\mathrm{PuO}_{2}$ with depleted $\mathrm{UO}_{2}$, pressing, sintering, and grinding. The loading of the pellets into elements and closure welding are to be done at LANL for the U.S. fuel and at Bochvar for the R.F. fuel. The assembly of elements into the bundle and necessary tests and characterization prior to irradiation will be done at CRL. In addition, CRL will procure or fabricate the hardware and other elements to complete the bundle and do the necessary analyses to support the irradiation. Irradiation will be accomplished in the pressurized loops of the NRU reactor at CRL for a period of 1-1/3 years. The fuel will be examined to assess its performance in the hot cells at CRL and then placed in interim storage prior to eventual disposal in a geologic repository in Canada.

In the event that the test is continued with one or more of the remaining three contingency bundles, an additional plutonium loading and a second level of homogeneity will be included.

\section{OBJECTIVES}

The objectives of the test are twofold: to contribute to the data base, which would eventually qualify MOX fuel for the CANDU reactors, and to demonstrate the infrastructure involved in the disposition of excess weapons plutonium as MOX fuel in reactors.

For the generated data to be considered by the reactor licensing agency and to meet the NRU requirements, quality assurance (QA) requirements must be applied that are consistent with the requirements of the Canadian Standards Association N286 series for design and Z299 series for fabrication (other standards such as ISO 9000 or ANSI/ASME NQA-1 may be used where equivalence can be demonstrated). This test will produce data showing how production and processing variables, as well as the detailed design of the pellets themselves, affect the performance of the CANDU MOX fuel. The heat generation rates will bracket those expected in the Bruce reactors (if the full four bundles are tested) and provide meaningful data on the expected performance of the fuel. These comparisons will also be used to optimize the MOX fuel specifications and fabrication methods. Although these data are a significant first step, much additional work will be required to qualify MOX fuel for use in the Bruce reactors, including additional irradiations of the final fuel designs in the NRU reactor, zero power reactor physics measurements, critical heat flux measurements, and irradiation of prototype bundles in the Bruce reactors.

Completion of this test will demonstrate much of the infrastructure required to dispose of the excess weapons plutonium as MOX reactor fuel. Although only laboratory quantities of fuel and a research reactor are involved, all the required processes will be accomplished. The currently planned first bundle contains a total of $10.6 \mathrm{~kg}$ MOX with $280 \mathrm{~g}$ of plutonium. The full test involves about $54 \mathrm{~kg}$ of MOX, containing about $1040 \mathrm{~g}$ of plutonium. The plutonium from weapon components will be converted to oxide, fabricated into MOX pellets, then loaded into fuel elements and seal welded, transported, assembled into bundles, 
irradiated in a reactor, discharged, examined, and finally stored in an interim facility prior to eventual emplacement in a repository as spent fuel.

\section{ROLES AND RESPONSIBILITIES}

The test program is being sponsored and funded by the USDOE-MD with two exceptions: the NRU irradiation charges and the ultimate disposal of the fuel residues are funded by AECL, and the pit-to-oxide conversion in the Russian Federation is funded by Minatom. The USDOE-MD is responsible for overseeing the entire project to ensure that it is consistent with the program objectives. USDOE-MD will seek and arrange funding authority for the DOE laboratories and will arrange procurement authorization for the other parties. The Oakland Operations Office of USDOE is responsible for contracting with AECL (through AECL Technologies, Inc.) for its portion of the work. Oak Ridge National Laboratory (ORNL), as lead laboratory for reactor alternatives for fissile materials disposition, is managing the program for USDOE-MD. ORNL will coordinate and oversee the activities of the other parties to ensure success of the project and report on progress, schedule, and cost to USDOE.

As lead laboratory for the front end of the reactor alternatives and, in particular, the MOX fuel fabrication aspects, LANL is responsible for developing the process parameters and producing the U.S. test MOX fuel in accordance with AECL product specifications and drawings. LANL will secure a source of weapons-derived $\mathrm{PuO}_{2}$ feed stock, including the available technical data showing its processing and characteristics. LANL will also provide the required data on the characteristics of the finished fuel pellets and elements as specified in the AECL requirements. LANL will be responsible for the packaging, transportation, safeguards, and security of the finished fuel transfer to CRL.

AECL, as the design authority for CANDU MOX fuel, has the principal responsibility to ensure that the irradiation test program confirms the feasibility of the CANDU MOX option, identifies essential data on the required fabrication process parameters, and provides some of the data needed by Ontario Hydro and the licensing board in preparing for the mission fuel. AECL is also the operator of the NRU reactor where the test will be conducted and, as such, is responsible for ensuring that the test is designed and operated in compliance with all the safety and regulatory requirements. AECL is the contracting agent with Bochvar for the R.F. fuel. AECL is providing specifications, drawings, and fabrication guidance to both LANL and Bochvar and will examine the finished fuel pellets and accompanying data reports to ensure that they meet the requirements of the test. $\mathrm{AECL}$ will supply depleted $\mathrm{UO}_{2}$, element claddings, and end plugs to both fabricators. AECL will also design and fabricate or procure non-MOX fuel elements for the bundles, fixed and demountable bundle hardware, and assemble the elements into bundles. AECL will perform the necessary tests and calculations and provide the documentation to permit test insertion, conduct the test including periodic reconfiguration of the demountable bundles, perform postirradiation examination, package and dispose of the irradiated waste materials, and report the test results. AECL will arrange to fund the prorated share of the NRU operating costs (irradiation unit charges estimated at $\$ 2.5 \mathrm{M}$ for the full test). AECL will have responsibility for transportation, safeguards, and security of the shipment of Bochvar fuel from the Russian Federation to CRL. 


\section{TEST DESCRIPTION}

The reference design of CANDU MOX fuel is based on the 37-element bundle, which is the most common CANDU design. These bundles ${ }^{2}$ contain depleted uranium as $\mathrm{UO}_{2}$ for the matrix in all the elements. The depleted $\mathrm{UO}_{2}$ is mixed with $5 \%$ dysprosium as the oxide (a burnable neutron absorber) in the central 7 elements, with $2.0 \%$ plutonium (percent plutonium refers to percentage of heavy metal) as $\mathrm{PuO}_{2}$ in the third ring of 12 elements, and with $1.2 \%$ plutonium as $\mathrm{PuO}_{2}$ in the outer 18 elements. With a bundle average burnup of $9.7 \mathrm{GWd} / \mathrm{MTHM}$ (metric tons of heavy metal), this fuel design would disposition about $1 \mathrm{MT}$ of weapons-grade plutonium per year per reactor. To increase the disposition rate, a new design ${ }^{3}$ contains $3.1 \%$ and $1.6 \%$ plutonium in the third and outer rings respectively. The dysprosium content of the inner elements is increased to $15 \%$. This fuel design can disposition $1.5 \mathrm{MT}$ weapons-grade plutonium per reactor per year at the same average burnup. The Parallex test addresses this new design of the CANDU MOX fuel. (Another design that could be implemented later in the mission, the CANFLEX 43-element bundle, has a higher plutonium content but is not included in this test.)

For a thorough description of the test and the test matrix refer to the Technical Overview Document. ${ }^{4}$ A brief summary is presented here. The content of the four test bundles is described in Table 1. The test bundles for the NRU reactor are similar in cross section to the standard CANDU 37-element bundle. The center element is removed to accommodate a guide tube for assembling the bundles vertically in the NRU test loops. The NRU reactor has two pressurized test loops that provide three vertical test sections in which essentially identical irradiation conditions can be attained. Each test section has six axial positions for the CANDU-size bundles: positions 1 and 6 on the ends are lower flux, positions 2 and 5 are intermediate flux, and positions 3 and 4 adjacent to the reactor centerline are the highest flux. Within the 37-element bundle, the linear heat ratings are different for the various rings, and the heat rating of the bundle as a whole may

Table 1. Parallex test matrix

\begin{tabular}{lcll}
\hline Bundle $^{a}$ & $\begin{array}{c}\text { Plutonium } \\
\text { (wt \%) }\end{array}$ & Homogeneity & \multicolumn{1}{c}{ Power rating } \\
\hline BD-1 & 3.1 & High & Low, intermediate, high \\
BD-2 & 3.1 & Intermediate & Low, intermediate, high \\
DM-1 & 1.6 & High, intermediate & High \\
DM-2 & 1.6 & High, intermediate & Intermediate \\
\hline
\end{tabular}

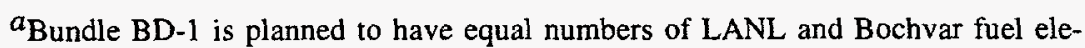
ments and to be inserted in early 1998. If enough MOX elements are not available to fill the bundle, low-enriched uranium elements will be substituted. Bundle BD-2 will be of the same design with natural uranium in the outer ring so that test conditions will be the same for the intermediate homogeneity fuel. The insertion of Bundles BD-2, DM-1, and DM-2 are contingent upon decisions on the CANDU option. 
be varied by the addition of more or less neutron absorbing or fissionable material. These variables allow the full test to be tailored to bracket the range of heat ratings calculated for the MOX fuel in the Bruce A reactors. These calculated heat ratings have been designated for this test as low ( 35 to $45 \mathrm{~kW} / \mathrm{m}$ ), intermediate $(45$ to $55 \mathrm{~kW} / \mathrm{m})$, and high $(55$ to $65 \mathrm{~kW} / \mathrm{m})$. Throughout the test, data will be acquired on loop power, and reactor conditions and fuel bundle powers will be calculated and documented for each irradiation period. At the completion of irradiation, elements will be cooled for about 3 months in the spent fuel bays prior to postirradiation examination (PIE).

First bundle. The first bundle BD-1, which is the only bundle currently planned for insertion, will be a fixed bundle containing $3.1 \%$ plutonium of high homogeneity. The cross section of the bundle is shown in Fig. 1. The fixed bundle, with the MOX elements in the inner rings, is required to accommodate the higher fissile content of the $3.1 \%$ plutonium elements in NRU. It will be placed in position 6 at the bottom of the loop stringer for 100 effective full-power days and then moved to position 1 at the top of the stringer for about a year. The axial gradients in the elements will produce all three power ratings in the bundle. In addition, the lower portions of the elements will undergo a substantial power increase in the move from position 6 to position 1 .

Contingency bundles. The contingency Parallex bundles consist of one additional fixed bundle and two special "demountable" bundles in which the outer 18 elements are mechanically fixed and may be
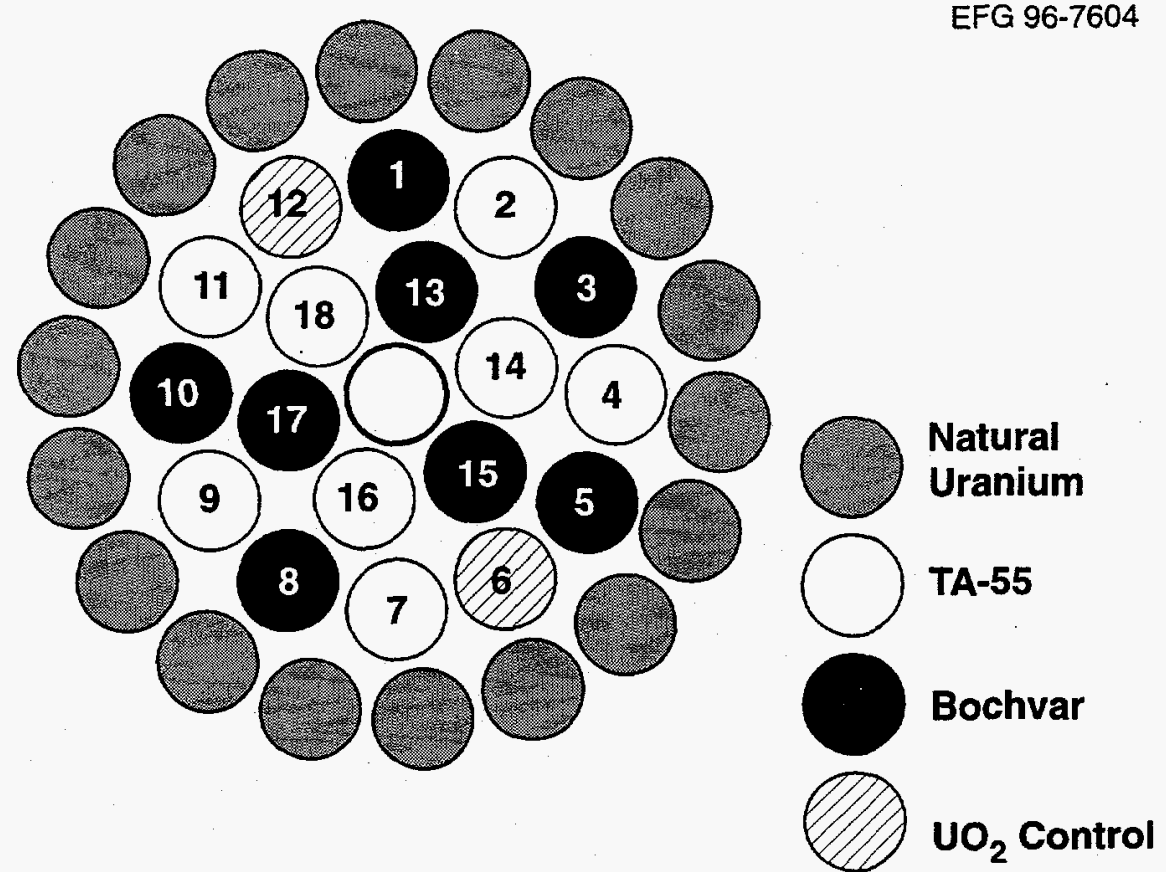

Fig. 1. Schematic cross section of a fixed bundle (BD-1 and BD-2). The central tube is the guide tube, and the next two rings are the experimental elements. Both bundles will contain natural $\mathrm{UO}_{2}$ in the outer elements. See Table 1 for definition of BD-1 and -2 . 
removed and replaced in the pool between reactor cycles. The fixed bundle will be identical to the first bundle, BD-1, except for the fuel homogeneity. The demountable bundles are used for the $1.6 \%$ plutonium elements with the test elements in the outer detachable ring. The cross section of a demountable bundle is shown in Fig. 2. The inner two rings contain natural $\mathrm{UO}_{2}$ elements in one case and depleted $\mathrm{UO}_{2}$ mixed with $5 \%$ dysprosium to lower the power in the second case. The fixed bundles are used for the $3.1 \%$ plutonium elements with the test elements in the center two rings to lower the heat ratings. The outer ring contains natural $\mathrm{UO}_{2}$ elements. This arrangement of the elements, combined with axial position in the loop, allows the $3.1 \%$ plutonium MOX to be tested at all three linear heat ratings and the $1.6 \%$ plutonium MOX to be tested at the high and intermediate linear heat ratings.

The demountable bundles will be removed to the spent fuel bays, and eight of the demountable elements from each bundle will be replaced after about $100 \mathrm{~d}$ in the reactor. Visual examinations will be conducted during these handling operations in the bays.

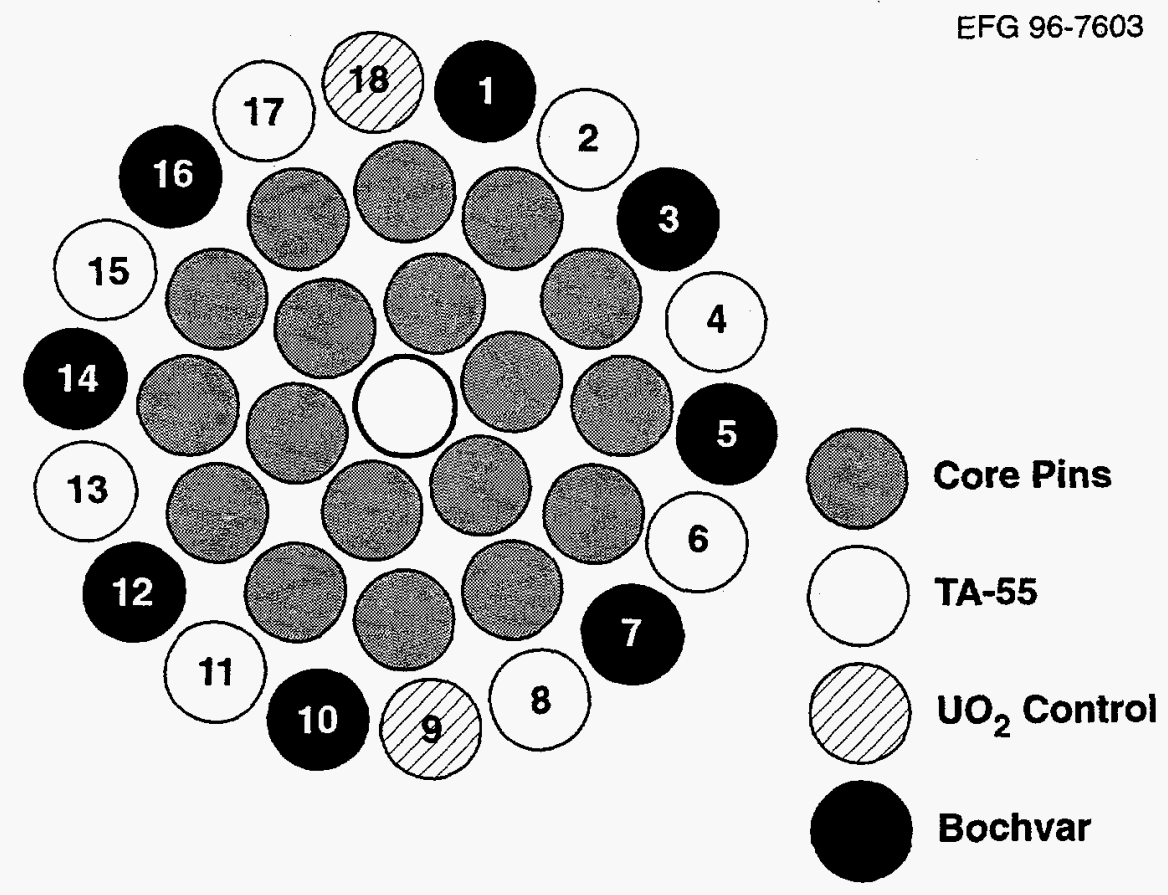

Fig. 2. Schematic cross section of a demountable bundle (DM-1 and DM-2). The central tube is the guide tube, the core elements are the next two rings, and the outer ring contains the 18 removable elements. DM-1 is to contain natural $\mathrm{UO}_{2}$ core elements, and DM-2 is to contain depleted $\mathrm{UO}_{2}$ with $5 \%$ dysprosium. See Table 1 for definition of DM-1 and -2 . 


\section{DISCUSSION OF TEST MATRIX}

The intent of this test is to fabricate and irradiate CANDU MOX fuel with a limited number of parameters controlled within specific ranges. The variables for the full test include the two levels of plutonium proposed for the initial Bruce $\mathrm{A}$ fuel, two levels of $\mathrm{PuO}_{2}$ homogeneity, and the three linear heat ratings to cover the complete range expected for MOX fuel in the Bruce reactors. Other fuel characteristics that could be expected to affect the fuel performance will be carefully controlled and/or monitored but will not be intentionally varied. The single bundle will not contain any material variables (other than fabricator) but will serve as a demonstration test of MOX performance at the power ratings expected in the Bruce reactors.

The level of $\mathrm{PuO}_{2}$ homogeneity attainable by the various commercial MOX fabrication processes has historically been a basis for claiming superiority of one process or another. The primary incentive to date for attaining a very finely dispersed $\mathrm{PuO}_{2} \mathrm{mix}$ in LWRs, the ability to dissolve the fuel easily in reprocessing, does not apply here because the fuel will not be reprocessed; however, there is some reason to think that $\mathrm{PuO}_{2}$ homogeneity could affect the CANDU MOX fuel performance. Although the $\mathrm{PuO}_{2}$ homogeneity within the range produced by the current commercial MOX processes does not appear to affect the LWR fuel performance, the peak linear heat ratings for the CANDU fuel in the Bruce A reactors are about 55 $\mathrm{kW} / \mathrm{m}$ compared to typical peak ratings of about $30 \mathrm{~kW} / \mathrm{m}$ in LWRs. Large $\mathrm{PuO}_{2}$-rich areas could affect the burnup threshold where increasing gas release begins or could produce hot spots on the cladding. In contrast, arbitrarily setting a very tight specification on homogeneity could possibly eliminate one of the existing commercial processes from consideration or could add unnecessarily to MOX powder processing costs. The extensive experience and data base for fabrication and operation of CANDU fuel relies on the properties of the $\mathrm{UO}_{2}$ feed material. If satisfactory performance is shown in the reactor, there may be advantages to sacrificing some degree of fuel homogeneity to obtain a MOX fuel that fabricates more like the standard $\mathrm{UO}_{2}$ feed material.

The degree of $\mathrm{PuO}_{2}$ homogenization in the $\mathrm{UO}_{2}$ matrix will be intentionally varied during fuel fabrication by the method of blending/milling the fuel mix. This can be accomplished in both laboratories with existing equipment. In both levels of homogeneity, a master mix will be produced. This master mix will then be blended down to the required compositions of $1.6 \%$ and $3.1 \%$ plutonium. The exact techniques for producing the two homogeneity levels will be developed at each laboratory. The homogeneity produced in each case will be characterized with the best available techniques. LANL is investigating the scanning electron microscope (SEM) and the microprobe in addition to autoradiography. The weapons-grade plutonium has a lower alpha activity than the reactor-grade plutonium, and the autoradiography technique for measuring homogeneity will need to be qualified as an adequate technique to measure homogeneity. These data will be used later in establishing specifications for the mission fuel.

The test matrix for the full test shown in Table 1 thus requires four batches of fuel produced by each fabricator. The numbers of elements of each type and the total quantity of MOX from each fabricator are shown in Table 2. Eight elements will be removed from each of the demountable bundles after about 5-GWd/MTHM burnup and replaced with fresh elements. The remainder of the test will be irradiated to the peak burnup of about $15 \mathrm{GWd} / \mathrm{MTHM}$, which is expected in the Bruce A reactors. The removal and 
Table 2. Quantity of elements and MOX from each fabricator for full test

\begin{tabular}{llcc}
\hline \multicolumn{1}{c}{ MOX type } & Number of elements & $\begin{array}{c}\text { MoX } \\
(\mathbf{k g})\end{array}$ & $\begin{array}{c}\text { Plutonium } \\
(\mathbf{k g})\end{array}$ \\
\hline 1.6\% Plutonium, intermediate homogeneity & $14(8+4+2)^{a}$ & 8.2 & 0.12 \\
1.6\% Plutonium, high homogeneity & $14(8+4+2)$ & 8.2 & 0.12 \\
3.1\% Plutonium, intermediate homogeneity & $9(8+1)^{b}$ & 5.3 & 0.14 \\
3.1\% Plutonium, high homogeneity & $9(8+1)$ & 5.3 & 0.14 \\
Total & 46 & 27 & 0.52 \\
\hline
\end{tabular}

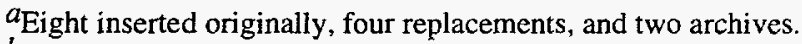

$b_{\text {Eight inserted plus one archive. }}$

replacement will give intermediate burnup data on the $1.6 \%$ plutonium elements at about 5 and 10 GWd/MTHM.

Other fuel characteristics that may affect performance but that will not be intentionally varied include surface finish, impurity content, density, pore size and distribution, and oxygen-to-metal (O/M) ratio. The density, pore distribution, $\mathrm{O} / \mathrm{M}$ ratio, and other parameters are not expected to be affected greatly by the $\mathrm{PuO}_{2}$ additions, and the normal $\mathrm{UO}_{2}$ CANDU pellet specification will be used. The surface finish may be affected because dry centerless grinding is desirable for the MOX, whereas wet centerless grinding is normally used for the CANDU pellets. The surface finish is important because it influences heat transfer from the pellet to the cladding. It is hoped that the dry grinding will produce a finish that meets the usual specification; however, this requirement may be relaxed if necessary. The impurity content is of concern primarily because of the gallium, which is present as an alloying agent in the weapons-grade plutonium. There is no experience to indicate whether gallium would be a problem. It has the potential to affect inreactor performance of the fuel through such mechanisms as stress corrosion cracking of the cladding or to affect the microstructural evolution of the fuel and thus its behavior. Preliminary evidence shows that much of the gallium is removed during normal fabrication by lubricant removal and sintering. However, as a conservative measure, the LANL $\mathrm{PuO}_{2}$ powder will be given a calcining treatment in a reducing atmosphere prior to blending, which has been shown to reduce the gallium substantially. The gallium content of the final pellets is expected to be $<15 \mathrm{ppm}$. The gallium content of the R.F. $\mathrm{PuO}_{2}$ is not known currently; however, it is expected that aqueous processing will be used to remove essentially all the major impurities including gallium. Gallium content will be carefully monitored in this test, but will not be an intentional variable. (The effects of gallium are to be studied out-of-reactor and in the LWR demonstration tests.) Other impurities are not expected to be outside the CANDU specification but will be monitored.

Each bundle will contain two control (or comparison) elements of $\mathrm{UO}_{2}$ with low-enriched uranium (LEU) so that the power rating is the same as the MOX elements. The primary evaluation criterion will be the performance of the MOX fuel under the Bruce A conditions as closely as they can be produced in the $\mathrm{NRU}$ reactor loops. The $\mathrm{UO}_{2}$ controls will provide a standard of comparison to the large $\mathrm{UO}_{2}$ data base. 


\section{POSTIRRADIATION EXAMINATION}

A detailed PIE plan will be prepared and approved at the completion of irradiation and prior to the start of destructive examination. Because fuel elements will become available at different times following the discharge and cooling, the PIE will be conducted in batches. The PIE data from each campaign will be documented separately, and an overall PIE report will be prepared to summarize cross comparisons.

An important output from the PIE tasks will be a summary of the Parallex MOX fuel performance as a function of the homogeneity levels and the various power levels during the NRU irradiation. Conclusions will be drawn about performance that would be expected under conditions in the Bruce A reactors.

All of the PIE data will be compared to preirradiation characterizations of the elements and data for the archive samples to quantify changes during irradiation and to assess whether these changes are consistent with those expected based on prior knowledge of CANDU fuel performance. The data on irradiation conditions will be used to perform computer code fuel performance simulations to predict measured parameters such as gas release, strain, void volumes, and grain size. The quantities in some of the PIE dis cussion below refer to the full four-bundle test matrix. If only the currently planned first bundle is irradiated, these quantities will necessarily be reduced.

Visual examination and profilometry. Each element will be examined visually along its length with the stereomicroscope. Photographs and videotape will be taken as required. Element diameters and profiles will be measured over the entire length at three orientations.

Axial gamma scans. Five fuel elements from each bundle will be axially scanned for gross gamma activity and isotopic activities $\left({ }^{137} \mathrm{Cs},{ }^{95} \mathrm{Nb},{ }^{154} \mathrm{Eu},{ }^{95} \mathrm{Zr}\right.$, and $\mathrm{Ru} /{ }^{106} \mathrm{Rh}$ ) at 1 -mm intervals to check for flux peaking and pellet-to-pellet gaps. The fuel element is rotated at $1 \mathrm{rps}$ while the gamma spectrum is being collected.

Element puncture and fission gas analysis. Ten elements will be punctured to determine gas volumes and end-of-life internal pressures. A sample of the gas from five of the ten elements will be analyzed by mass spectrometry to measure the fission gas composition and the xenon and krypton isotopic composition.

Ceramographic and metallographic examination. Samples will be cut from the axial midplane of ten fuel elements from each bundle for optical microscope examination of the fuel and sheath. Samples will also be cut from both ends of five of the elements. Oxide thickness on the inner and outer surfaces of the sheath and inner sheath liner retention will be measured in the as-polished condition. The fuel will be chemically etched to examine the grain growth, porosity, and fuel sheath interface. Finally, the sheath will be etched to examine the microstructure and hydride distribution. Photographs will be taken as required. The distribution of heavy elements and fission products will be examined on samples from five elements with the use of alpha/beta autoradiography.

Burnup analysis. Samples will be cut from the peak flux position in five elements for burnup measurement. The fuel is chemically dissolved, and burnup is determined by high-performance liquid chromatography, which uses ${ }^{139} \mathrm{La}$ as a fission monitor. The need for isotopic analysis is avoided because ${ }^{139} \mathrm{La}$ is monoisotopic in fission. 
Sheathing hydrogen analysis. Samples will be cut from five elements for the analysis of hydrogen content in the sheathing. The fuel is removed using a combination of chemical and mechanical methods. The hydrogen content of each sample is determined by vacuum extraction mass spectrometry.

SEM examinations. Fuel cross sections from five elements will be examined with the SEM to check for plutonium homogeneity in the fuel matrix. Image analysis will be used to quantify the plutonium homogeneity in the irradiated fuel.

$\mathbf{O} / \mathbf{M}$ and microdensity measurement. Thin cross sections of fuel from two elements will be cut into small samples at several radial positions using a numerically controlled saw. These samples will have their densities determined using an immersion technique with a high-precision micro-balance to yield information on densification and swelling. $\mathrm{O} / \mathrm{M}$ ratios will be measured on the samples using coulometric titration.

\section{QUALITY ASSURANCE REQUIREMENTS}

For the data produced to be acceptable to the licensing board and for the experiment to be accepted by the NRU reactor, a QA program essentially equivalent to ASME/ANSI NQA-1 is required. The Parallex project will implement a QA program in accordance with the requirements of the AECL Management Manual (00-1914-MAN-014). This QA program satisfies the requirements of the Canadian Standards Association (CSA) N286 series. The project will specifically apply the CSA N286.2 standard to ensure that the irradiation and PIE phases of the project are planned, documented, and verified. The procurement documents will address the QA requirements placed on the suppliers of fuel, control elements, filler elements, and hardware. AECL will supply specifications and drawings to the fuel fabricators and will review and approve the fabricators' QA plans and fabrication and test plans to ensure that they meet the essential requirements.

\section{SCHEDULE AND COST}

The original schedule was for insertion of the first test bundle before the end of CY 1996. The delay in obtaining a contract with Bochvar and a delay in obtaining the export license for the LANL fuel made it impossible to meet this goal. It now appears probable that a contract can be signed in June 1997 and that the first bundle could be inserted in early 1998 (Fig. 3). Figure 4 shows that PIE of this first bundle could be completed in 2000. Bundle BD-1 will consist of an equal mix of Bochvar and LANL fuel containing $3.1 \%$ plutonium of high homogeneity. Bundle BD-2, if built, will then consist of an equal mix of LANL and Bochvar fuel of intermediate homogeneity and will be the same design as BD-1. If built, bundles DM-1 and DM-2 will consist of an equal mix of Bochvar and LANL fuel containing 1.6\% plutonium of high and intermediate homogeneity, respectively. The contingency three bundles (BD-2, DM-1, and DM-2) are to be fabricated and inserted only upon further approval and guidance from USDOE-MD. Figure 4 shows that completion of PIE for the remaining three bundles can be completed 3 years after the decision to proceed. 
ORNL-DWG 97-2202 EFG

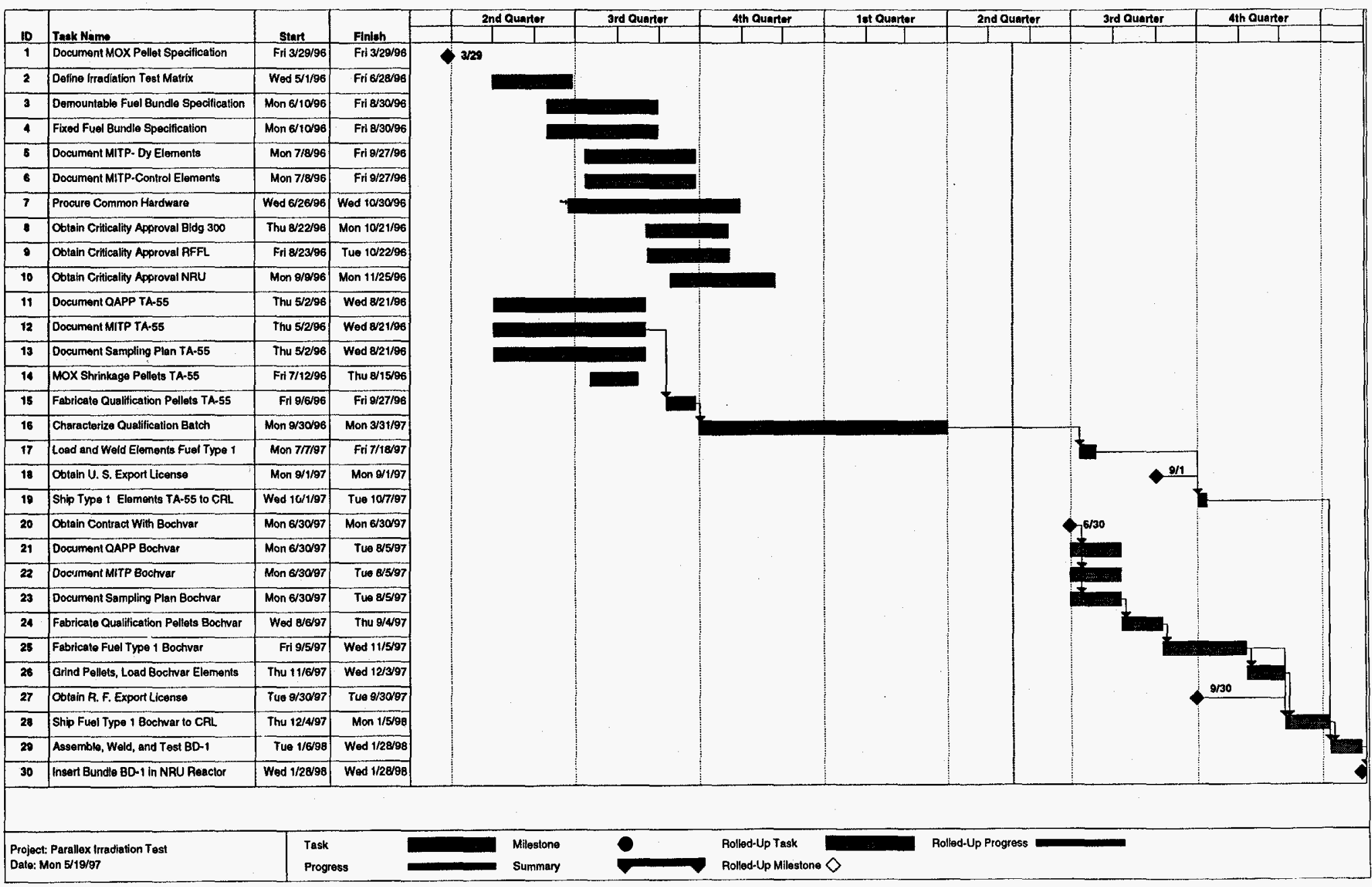

Fig. 3. Parallex schedule for insertion of first bundle. 
ORNL-DWG 97-2203 EFG

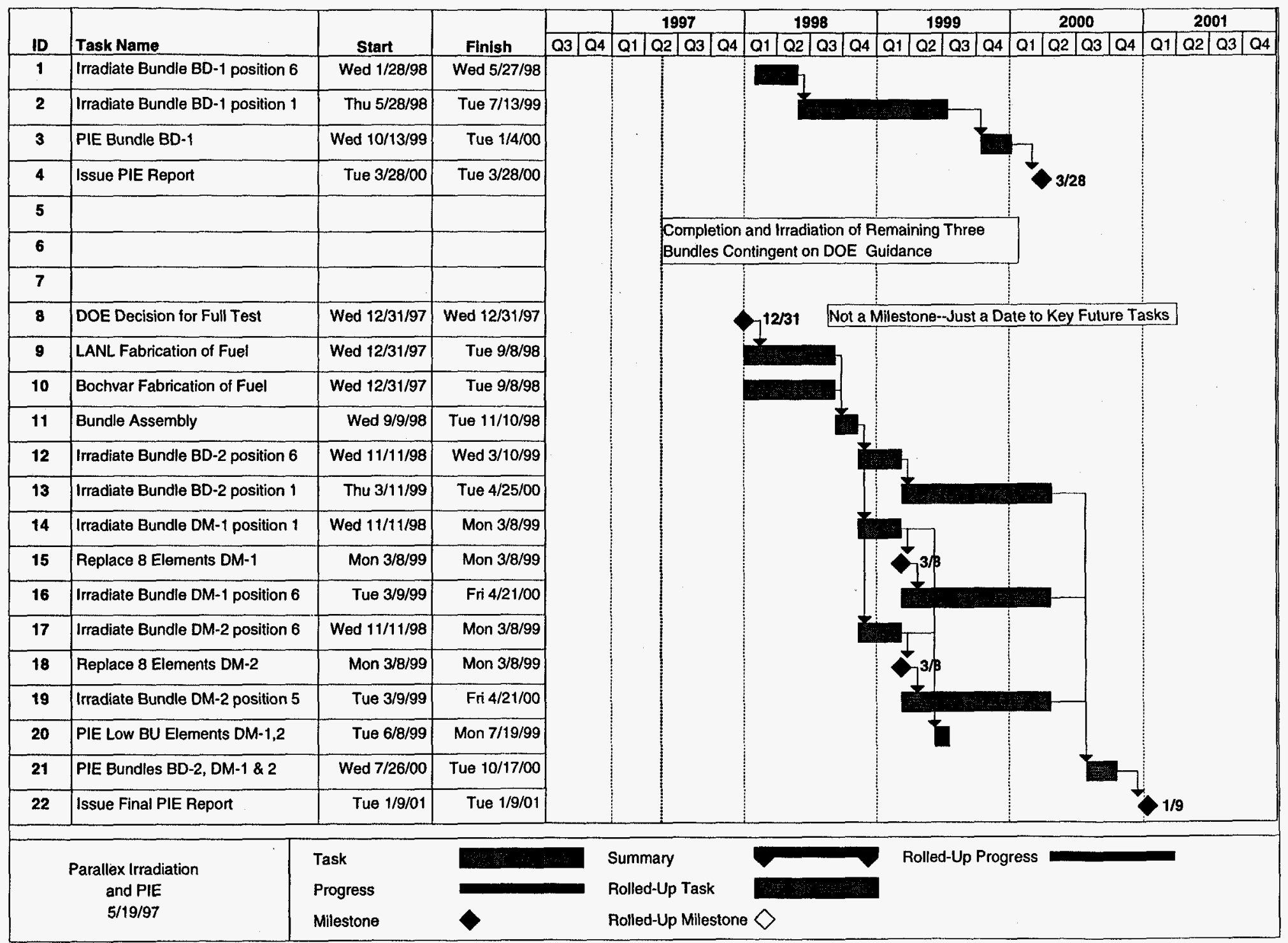

Fig. 4. Parallex irradiation and PIE schedule for the first bundle and for three contingency bundles. 
The projected costs for the task are in Table 3 by facility and fiscal year. Additional funding that may be required for the final three bundles is not included. The funding of the Parallex test is directly from USDOE-MD to the various participants with the exception of the Bochvar work. Thus, the annual operating plan for ORNL and LANL will include Parallex funds. AECL is funded through a contract with AECL Technologies, Inc., administered by the Oakland Operations Office of USDOE. The funding for Bochvar to produce four batches of fuel for the test will be from a contract with AECL. The formal accounting for the Parallex work will thus be through the normal legal channels. However, as program manager, ORNL will report monthly on costs and project status to USDOE-MD.

Table 3. Parallex costs

\begin{tabular}{|c|c|c|c|c|c|}
\hline \multirow[b]{2}{*}{ Facility } & \multicolumn{5}{|c|}{ Costs (\$K) } \\
\hline & FY $1996^{a}$ & FY 1997 & FY 1998 & FY 1999 & FY 2000 \\
\hline AECL & 480 & $2200^{b, c}$ & 200 & 850 & 75 \\
\hline LANL & 1390 & 895 & & & \\
\hline ORNL & 100 & 250 & 200 & 100 & 50 \\
\hline $\begin{array}{r}a_{\mathrm{A}} \\
b_{\mathrm{F}} \\
\text { less grinde } \\
{ }_{\mathrm{C}} \\
\text { occur in } \mathrm{F}\end{array}$ & $\begin{array}{l}\text { tual costs. } \\
1997 \text { costs } \mathrm{f} \\
\text { for Bochvar a } \\
1997 \text { costs in } \\
1998 \text { if full te }\end{array}$ & $\begin{array}{l}\text { AECL incl } \\
\$ 170 \mathrm{~K} \text {. } \\
\text { ude } \$ 210 \mathrm{~K} \\
\text { continues. }\end{array}$ & $\begin{array}{l}\text { e analyti } \\
\text { nmitmen }\end{array}$ & $\begin{array}{l}\text { quipment } \\
\text { Bochvar }\end{array}$ & did a center- \\
\hline
\end{tabular}

\section{SUMMARY}

This document describes a plan to jointly irradiate U.S. and R.F. MOX fuel in the NRU reactor at Chalk River, Canada, in a test to demonstrate the feasibility of using the four Bruce A CANDU reactors to disposition excess weapons plutonium. Fuel performance data generated in the test will be applicable for consideration toward fuel qualification should the mission proceed. The test is sponsored and funded by USDOE-MD and is managed by ORNL. AECL has the primary technical responsibility of test design, operation, and PIE. AECL will also fund the irradiation charges at the NRU. The U.S. fuel will be fabricated by LANL in their TA-55 facility. The R.F. fuel will be fabricated by the Bochvar Institute. AECL is responsible for the contracting and funding of the Bochvar effort.

The test matrix and scope for this plan describe the originally envisioned four-bundle test for Parallex. However, recent developments have narrowed the immediate scope to one shared U.S./R.F. bundle to be inserted in early 1998. The remaining three contingency bundles will be fabricated and inserted only after further guidance from USDOE-MD. The PIE is scheduled to be completed in 2000. The full test consists of two concentrations of $\mathrm{PuO}_{2}$ appropriate to the first mission loading of the Bruce A reactors at two levels of homogeneity. The first (and only currently planned) bundle has one $\mathrm{PuO}_{2}$ concentration with high 
homogeneity. The linear heating rates will be similar to those expected in the Bruce A reactors. Completion of the PIE for the final three bundles can be completed 3 years after the decision to proceed with them.

\section{REFERENCES}

1. Record of Decision for the Storage and Disposition of Weapons-Usable Fissile Materials Final Programmatic Environmental Impact Statement, U.S. Department of Energy, January 14, 1997.

2. Plutonium Consumption Program: CANDU Reactor Project Final Report, AECL Technologies, Inc., July 31, 1994.

3. Optimization and Implementation Study of Plutonium Disposition Using Existing CANDU Reactors, AECL Technologies, Inc., September 1996.

4. Chalk River Laboratories, Technical Overview, CANDU MOX Fuel Dual Irradiation Experiment, Parallex Project, 100-37000-TD-001, Rev. 1.0, AECL, August 1996. 
ORNL/TM-13302

Dist. Category UC-523

\section{INTERNAL DISTRIBUTION}
1. B. B. Bevard
2. S. L. Byerly
3-7. G. L. Copeland
8. B. S. Cowell
9. E. C. Fox
10. R. G. Gilliland
11. S. R. Greene
12. S. A. Hodge
13. S. B. Ludwig
14. G. T. Mays
15. G. E. Michaels

16. D. L. Moses

17. D. G. O'Connor

18. R. T. Primm, III

19. C. C. Southmayd

20. D. J. Spellman

21. Central Research Library

22. Y-12 Technical Library

23. ORNL Patent Section

24-25. ORNL Laboratory Records (OSTI)

26. ORNL Laboratory Records-RC

\section{EXTERNAL DISTRIBUTION}

27. M. L. Adams, ANRCP, Texas A\&M University, Dept. of Nuclear Engineering, Zachry 129, College Station, TX 77843.

28. J. Baker, U.S. Department of Energy, MD-3, 1000 Independence Avenue SW, Washington, DC 20585.

29. C. Beard, Los Alamos National Laboratory, P.O. Box 1663, MS-F607, Los Alamos, NM 87545.

30. T. Blair, Los Alamos National Laboratory, P.O. Box 1663, Los Alamos, NM 87545.

31. J. J. Buksa, Los Alamos National Laboratory, P.O. Box 1663, MS-K551, Los Alamos, NM 87545.

32. H. R. Canter, U.S. Department of Energy, MD-3, 1000 Independence Avenue SW, Washington, DC 20585.

33. K. Chidester, Los Alamos National Laboratory, P.O. Box 1663, Los Alamos, NM 87545.

34. D. Cox, AECL Chalk River Laboratories, Chalk River, Ontario, Canada K0J 150.

35. A. I. Cygelman, U.S. Department of Energy, MD-3, 1000 Independence Avenue SW, Washington, DC 20585.

36. J. Didlake, Sandia National Laboratories, Rosslyn Office, 1401 Wilson Blvd., Suite 1050, Arlington, VA 22209.

37. F. C. Dimayuga, AECL Chalk River Laboratories, Chalk River, Ontario, Canada K0J 150.

38. S. Eaton, Los Alamos National Laboratory, P.O. Box 1663, Los Alamos, NM 87545.

39. H. Feinroth, Gamma Engineering Corp., 15815 Crabbs Branch Way, Rockville, MD 20855.

40. R. Gadsby, AECL Technologies, Inc., 2251 Speakman Drive, Mississauga, Ontario, Canada L5K $1 \mathrm{~B} 2$.

41. V. Georgiadas, AECL Technologies, Inc., 1155 Metcalfe Street, Montreal Quebec, Canada H3B 2 V6.

42. E. G. Cumesty, ORNL Site Manager, DOE-ORO, Oak Ridge, TN 37831-6269.

43. D. Klein, ANRCP, University of Texas at Austin, ECJ10.334 MC C2100, Austin, TX 78712-1080.

44. Z. Klobucar, AECL Technologies, Inc., 1155 Metcalfe Street, Montreal Quebec, Canada H3B 2 V6.

45. J. C. Luxat, Ontario Hydro, 700 University Avenue, H11-F1, Toronto, Ontario, Canada M5G 1 X6. 
46. D. J. Nulton, U.S. Department of Energy, MD-4, 1000 Independence Avenue SW, Forrestal Bldg., Room 6G-050, Washington, DC 20585.

47. S. L. Passman, Sandia National Laboratories, 1401 Wilson Blvd., Suite 10S0, Arlington, VA 22209.

48. D. Peko, U.S. Department of Energy, MD-3, 1000 Independence Avenue SW, Washington, DC 20585.

49. P. T. Rhoads, U.S. Department of Energy, MD-3, 1000 Independence Avenue SW, Washington, DC 20585.

50. J. I. Saroudis, AECL Technologies, Inc., 1155 Metcalfe Street, Montreal Quebec, Canada H3B 2 V6.

51. R. H. Steele, MPR Associates, Inc, 320 King Street, Alexandria, VA 22314-3238.

52. J. W. Toevs, Los Alamos National Laboratory, P.O. Box 1663, MS-F628, Los Alamos, NM 87545.

53. Headquarters FOIA Reading Room, U.S. Department of Energy, Room 1E-190, Forrestal Building, 1000 Independence Avenue SW, Washington, DC 20585, ATTN: Carolyn Lawson.

54. Los Alamos National Laboratory, U.S. Department of Energy, c/o Los Alamos Community Reading Room, 1450 Central, Suite 101, Los Alamos, NM 87544, ATTN: LANL Outreach Manager.

55. Oak Ridge Operations Office, U.S. Department of Energy, Public Reading Room, 200 Administration Road, P.O. Box 2001, Oak Ridge, TN 37831-8501, ATTN: Amy Rothrock. 